\title{
Shrinkage and swelling behavior of archaeological waterlogged wood preserved with slightly crosslinked sodium polyacrylate
}

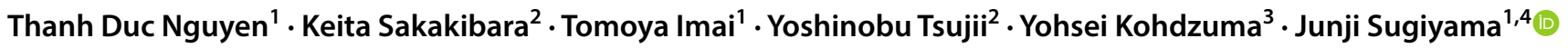

Received: 12 September 2017 / Accepted: 22 December 2017 / Published online: 29 January 2018

(c) The Japan Wood Research Society 2018

\begin{abstract}
In this article, the conservation of archaeological waterlogged wood (WW) of Afzelia sp. (medium degraded: $U_{\max }=385 \%$ ) was impregnated in vacuum with an aqueous solution of acrylic acid (AA), sodium acrylate monomer (AANa), crosslinking agent (MBA) and catalyst (V-501). The simultaneous in situ polymerization and crosslinking resulted in slightly crosslinked sodium polyacrylate (PAANa) in the wood structure. The results showed that untreated WW had only a very limited ability to re-swell to recover its original dimensions from a collapsed condition, while WW protected by crosslinked PAANa could almost fully recover its original shape and size even after several drying-rewetting cycles. From microscopic observations, treated wood was found to maintain its original cell structure, form and shape even after repeated drying-rewetting cycles. PAANa was observed to be densely localized near the middle lamella, the cell corners, and the cell lumina by transmission electron microscopy observation. These observations suggest that our PAANa treatment provides reasonable strength as well as favorable hydrophilicity to avoid hornification of the cell wall upon drying, thus providing unique shape recovery properties.
\end{abstract}

Keywords Archaeological waterlogged wood $\cdot$ Afzelia sp. $\cdot$ In situ polymerization $\cdot$ Shape recovery $\cdot$ Crosslinked sodium polyacrylate

\section{Introduction}

Archaeological waterlogged wood (WW) becomes considerably fragile over time because of chemical hydrolysis and biological deterioration in the wet buried environment [1, 2]. Because of the disintegration of cellulose, hemicellulose, and lignin, the microvoids within the wood cell walls become larger, making the wood more porous. As long as the gaps remain filled with water, WW can retain its shape $[3,4]$. In contrast to recent wood, in which drying stresses

Junji Sugiyama

sugiyama@ rish.kyoto-u.ac.jp

1 Research Institute for Sustainable Humanosphere, Kyoto University, Gokasho, Uji, Kyoto 611-0011, Japan

2 Institute for Chemical Research, Kyoto University, Uji, Kyoto 611-0011, Japan

3 Center for Archaeological Operation, Nara National Research Institute for Cultural Properties, 247-1 Saki-cho, Nara city 630-8577, Japan

4 College of Materials Science and Engineering, Nanjing Forestry University, Nanjing 210037, China and changes in shape can be largely sustained by the inherent strength of the material, WW often undergoes extreme levels of shrinkage upon drying, owing to two fundamental factors $[2,4,5]$. First, the decomposition of the carbohydrates in WW decreases the crystallinity of the remaining cellulose, which results not only in increased hygroscopicity but also in increased shrinkage parallel to the fiber direction. Second, the extreme shrinkage of WW is caused by the great loss in strength due to cell wall decomposition. As drying proceeds, the weakened cell walls are unable to withstand the stress imposed by the surface tension of the receding columns of liquid water, leading to collapse of the wood structure [6]. The decomposition of cellulose microfibrils is thought to be responsible for the weakening of the cell walls; a clear increase in longitudinal shrinkage, which can be as large as $10 \%$, can thus be considered an indicator of structure deterioration $[2,5]$.

Generally, the shrinkage of WW increases as the residual density decreases. A linear relationship has been observed between the maximum moisture content and volumetric shrinkage [5, 7]. During dehydration of the WW cellulose, strong molecular interactions cause cellulosic molecules to 
hide their hydrophilic surfaces, eliminating moisture and leading to extreme shrinkage [8]. In most cases, the collapse of the structure causes not only volumetric shrinkage, but also irreversible damage associated with distortions and numerous cracks $[2,3,8]$. Once such shrinkage and deformation has occurred, it is difficult to restore the WW to its original size and shape in common solvents, including water.

So far, several methods have been reported for the restoration of collapsed WW. Early investigations were conducted using low-concentration sodium hydroxide $(\mathrm{NaOH})$ solution $[3,9]$. However, $\mathrm{NaOH}$ solution, a strong alkali agent, accelerates the degradation of the remaining wood. Furthermore, the restoration performance is limited to a maximum of about $10 \%$ recovery $[2,3]$. Another method using mechanical swelling achieved by rapid decompression of supercritical $\mathrm{CO}_{2}$ fluid was also studied, and enabled partial or sometimes total recovery of the initial volume of the objects. However, sufficient viscosity of the treatment solution is of prime necessity to obtain effective swelling of very degraded collapsed wood and, therefore, total recovery of the initial shape was not obtained for very degraded collapsed wood [10]. More recently, treatment with lactic acid appeared to be effective in the re-swelling of once-dried WW for oak wood. However, based on visual inspection, this treatment is not free from degradation of the wall components, particularly lignin, due to acid-induced hydrolysis [11]. Additionally, an active alkali-urea treatment was developed to achieve total recovery of the initial shape; however, the degraded secondary wall was completely removed in the recovered WW [3]. This was the context in which we conducted our study to seek a novel and mild method for the restoration of WW.

Recently, a unique behavior was reported for bacterial cellulose (BC) in which acrylic acid and sodium acrylate were copolymerized and crosslinked in situ [12]. This crosslinked BC gel had excellent shape recovery after multiple drying and rewetting cycles because of the superabsorbent nature of PAANa [13, 14]. This phenomenon can be interpreted by considering the high osmotic pressure of PAANa gel, which absorbs a large amount of water in its three-dimensional networks and retains the absorbed water even under compression, drying, and shrinkage. The PAANa gel has high durability and stability in the swelling environment and during the storage [14]. Therefore, in this study, we investigated the applicability of this technique to WW as a potential tool for preservation from unexpected drying.

\section{Materials and methods}

\section{Sample preparation}

Archaeological sample was collected from the Thang Long Imperial Citadel excavation site in Hanoi, Vietnam, which is recognized in the UNESCO World Heritage list. The specimen was identified as Afzelia sp. based on microscopic anatomical observations. All the samples were taken from the same piece of wood. The saturated moisture content $\left(U_{\max }\right)$ was determined to be $385 \%$ based on weighing the wood samples before and after oven drying at $105^{\circ} \mathrm{C}$. The basic wood density was calculated to be $0.22 \mathrm{~g} / \mathrm{cm}^{3}$ based on the oven-dried weight of wood sample and its maximum water saturation volume. The WW was determined to be in a medium state of degradation [2]. The specimen was then cut into $20 \times 20 \times 5 \mathrm{~mm}$ blocks (tangential $\times$ radial $\times$ longitudinal dimensions).

Acrylic acid (AA), 4,4'-azobis (4-cyanopentanoic acid) (V-501) catalyst, and $N, N^{\prime}$-methylenebisacrylamide (MBA) crosslinking agent were purchased from Wako Pure Chemical Industries, Ltd., Japan. Sodium acrylate (AANa) monomer was obtained from Sigma-Aldrich, USA. All chemicals were used without further purification.

\section{Impregnation, in situ polymerization and crosslinking}

Figure 1 presents a flowchart of the process for the impregnation, in situ polymerization and crosslinking PAANa.

\section{Preparation of impregnation solution}

AA 98\% (1.2 g, $16 \mathrm{mmol})$, AANa $97 \%$ monomer $(0.50 \mathrm{~g}$, $5.3 \mathrm{mmol})$, and MBA (0.10 g, $0.6 \mathrm{mmol})$ crosslinking agent were solubilized in $10 \mathrm{~g}$ of distilled water under stirring in a test tube. Then, a given amount of the catalyst ( $\mathrm{V}-501$, $0.06 \mathrm{~g}, 0.2 \mathrm{mmol}$ ) was added to the stirred solution and fully dissolved by stirring.

\section{Vacuum impregnation of wood}

In the next step, the WW samples were placed in the test tube, which had been filled with impregnation solution. The test tube was equipped with a nitrogen inlet adapter. Impregnation was performed by impregnation under a low pressure of $0.1 \mathrm{MPa}$ for about $20 \mathrm{~min}$.

\section{Nitrogen bubbling and blanket}

In the next step, nitrogen gas was purged for $10 \mathrm{~min}$ to remove oxygen dissolved in the impregnation solution. The nitrogen blanket is necessary for many polymerizations because oxygen radical itself may stop polymerization or monomer radical formation. Hence, it is necessary to maintain an inert atmosphere. 
Fig. 1 Block diagram for the separate conservation steps of WW completed with slightly crosslinked PAANa
PREPARATION OF IMPREGNATION SOLUTION

- Acrylic acid 98\% (AA) (1.2 g, 16 mmol)

- $\quad$ Sodium acrylate $97 \%$ (AANa) monomer $(0.5 \mathrm{~g}, 5.3 \mathrm{mmol})$

- $\quad N, N^{\prime}$-methylenebisacrylamide (MBA) $(0.10 \mathrm{~g}, 0.6 \mathrm{mmol})$ crosslinking agent

- Distilled water $(10 \mathrm{~g})$

- Catalyst V-501 (0.06 g, $0.2 \mathrm{mmol})$

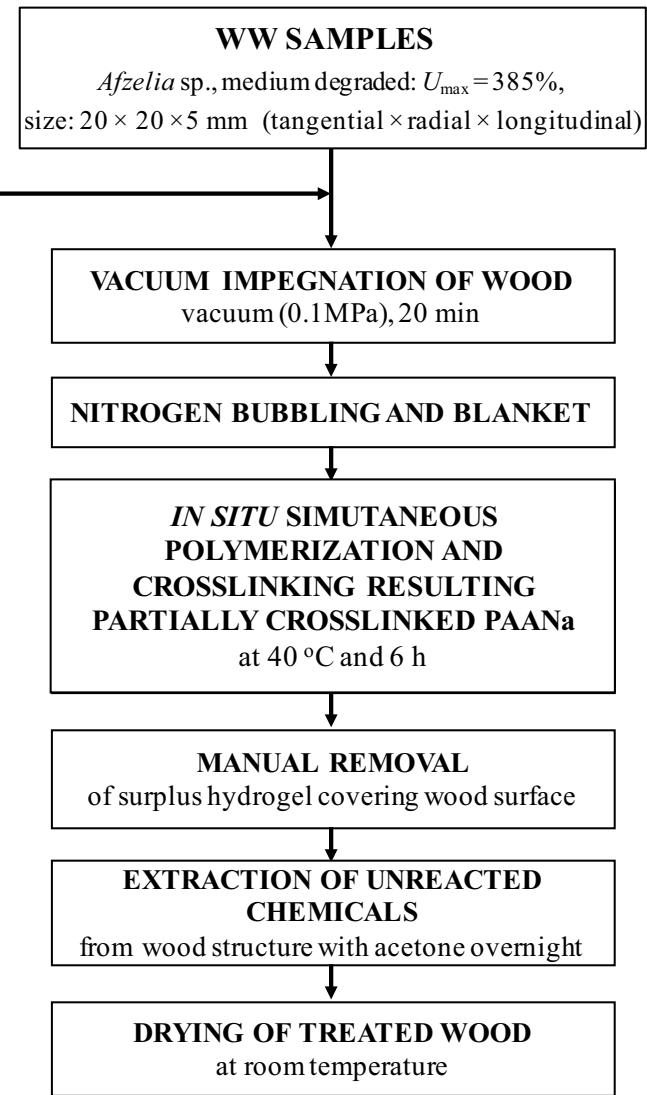

In situ simultaneous polymerization and crosslinking of impregnations resulting in partially crosslinked PAANa

For in situ temperature polymerization and crosslinking, the reactor was immersed in a thermo-controlled water bath and kept at $40{ }^{\circ} \mathrm{C}$ for $6 \mathrm{~h}$. The synthesis scheme for partially crosslinked PAANa is shown in Fig. 2.

\section{Manual removal}

The samples were removed from the obtained hydrogels. The surplus crosslinked polymer gel was removed manually from surface of the samples.

Fig. 2 Synthesis scheme for partially crosslinked PAANa

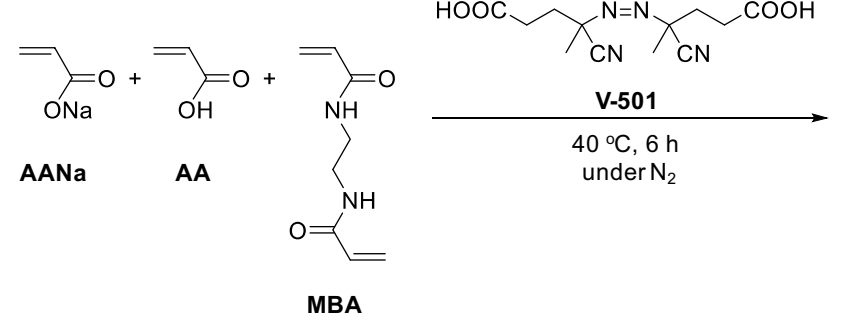

\section{Extraction of unreacted chemicals from wood structure}

In the next step, treated samples were immersed in acetone overnight to remove unreacted monomers and catalyst.

\section{Drying of treated wood}

The treated WW containing slightly crosslinked PAANa was dried at room temperature.

\section{Fourier-transform infrared microscopy}

For further investigation, it was essential to confirm the polymerization of the acrylic monomers inside the WW. 15- $\mu \mathrm{m}$ cross sections from untreated and PAANa-treated

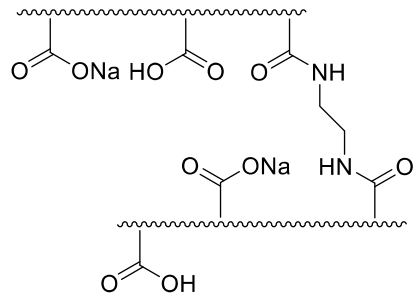

PAANa gel 
samples were prepared. Fourier-transform infrared (FTIR) microscopy was performed using a Spotlight 200 Frontier FTIR (PerkinElmer, USA) spectrometer connected to a microscope operated in transmission mode. The spectra from a section with an area of $30 \times 30 \mu \mathrm{m}$ were acquired in the range of $4000-400 \mathrm{~cm}^{-1}$ with a resolution of $4 \mathrm{~cm}^{-1}$. For each spectrum, 64 scans were collected.

\section{Shape recovery tests}

The shape recovery properties were investigated based on two drying-rewetting cycles.

In the first cycle, the untreated and treated samples, which were extracted from water and acetone, respectively, were air dried for 3 days. Both samples were then immersed in distilled water at room temperature until the dimensional changes reached a plateau. In the second cycle, the recovered samples were again air dried for 3 days and then reimmersed in distilled water to reach swelling equilibrium. The shrinkage and swelling ratios were calculated from sample images using Image-J software (https://imagej.nih.gov). The shrinkage and swelling along the longitudinal, radial, and tangential axes were quantified and evaluated by the restoration degree $(R)$

$\% R=\left(a_{\mathrm{i}} / a_{0}\right) \times 100$,

where $a_{0}$ are the dimensions of original untreated sample and $a_{\mathrm{i}}$ is the sample's dimensions after the 1 st drying, 1 st rewetting, 2nd drying, 2nd rewetting, respectively.

\section{Scanning electron microscopy}

The untreated and PAANa-treated specimens were prepared from internal part of samples. They were freeze dried for 4 days and then coated with platinum (JFC-1600, JEOL, Japan). A field emission scanning electron microscope (JSM-7800F prime, JEOL, Japan) was operated at an accelerating voltage of $1.5 \mathrm{kV}$.

\section{Transmission electron microscopy}

The wood blocks, $1 \times 1 \times 3 \mathrm{~mm}$ (tangential $\times$ radial $\times$ longitudinal dimensions), were prepared from the fully waterlogged condition of untreated and PAANa-treated samples. The treated sample was extracted from swelling equilibrium condition. Both samples were then substituted with acetone using the freeze-substitution method [15]. The blocks were then embedded in Spurr resin (EM S024, TAAB, England) [16]. Ultrathin sections with a $90 \mathrm{~nm}$ thickness were cut with an ultramicrotome (UItracut E; Leica, Berks, England) equipped with a diamond knife. The sections were stained with uranyl acetate and lead citrate [17] and observed using a transmission electron microscopy (JEM 1400, JEOL, Japan) operated at $120 \mathrm{kV}$.

\section{Results and discussion}

\section{In situ polymerization and crosslinking}

The Fourier-transform infrared spectra of the treated and untreated WW are shown in Fig. 3. Generally, the main characteristics of the treated wood were similar to those of untreated sample. The most significant difference between the two spectra is the band at $1707 \mathrm{~cm}^{-1}$, which is the absorption band corresponding to $\mathrm{C}=\mathrm{O}$ stretching of the polymer [18]. The presence of this critical absorption band indicated that PAANa was successfully polymerized inside the WW.

\section{Shrinkage and swelling behavior}

The changes in the shape of the PAANa-treated and untreated specimens during repeated drying-rewetting experiments are shown in Fig. 4. A significant difference between the shrinkage-swelling behaviors of the treated and untreated specimens was clearly observed. Although the specimens treated with PAANa recovered nearly their original volume even after two drying-rewetting cycles, the untreated samples could not recover their original shape and size after being dried once. The shrinkage-swelling behavior was monitored carefully along the three anisotropic axes.

During the first drying-rewetting cycle, the dimensions of the PAANa-treated and untreated samples shrank after air drying (Fig. $4 a_{1 d}$ and $b_{1 d}$ ). The results showed that the

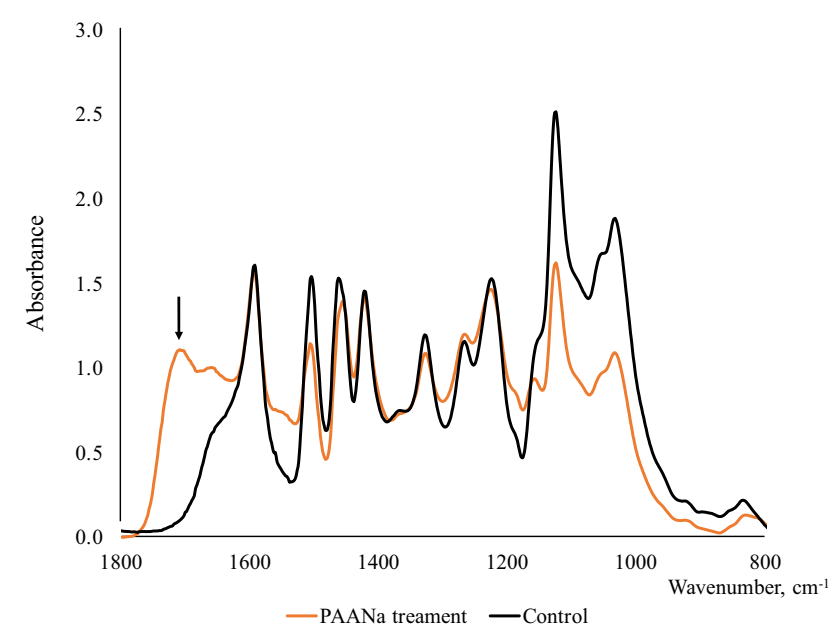

Fig. 3 Fourier-transform infrared spectra of PAANa-treated and untreated WW. Note that the $\mathrm{C}=\mathrm{O}$ absorbance at $1707 \mathrm{~cm}^{-1}$ is clearly observed in the spectrum of the PAANa-treated sample (arrow) 
Fig. 4 Repeated shrinkage-swelling cycles of WW samples. $\mathbf{a}_{0}-\mathbf{a}_{2 \mathrm{~s}}$ PAANa-treated $\mathrm{WW}, \mathbf{b}_{\mathbf{0}}-\mathbf{b}_{2 \mathrm{~s}}$ untreated WW, $\mathbf{c}_{\mathbf{0}}-\mathbf{c}_{2 \mathrm{~s}}$ shape recovery rate (\%), $\mathbf{a}_{\mathbf{0}}-\mathbf{c}_{\mathbf{0}}$ original samples, $\mathbf{a}_{\mathbf{1 d}}-\mathbf{c}_{\mathbf{1 d}}$ the first air-drying cycle, $\mathbf{a}_{1 \mathrm{~s}}-\mathbf{c}_{\mathbf{1 s}}$ the first swelling cycle, $\mathbf{a}_{\mathbf{2 d}}-\mathbf{c}_{\mathbf{2 d}}$ the second air-drying cycle, $\mathbf{a}_{2 \mathrm{~s}}-$ $\mathbf{c}_{2 \mathrm{~s}}$ the second swelling cycle; scale bar $5 \mathrm{~mm}$

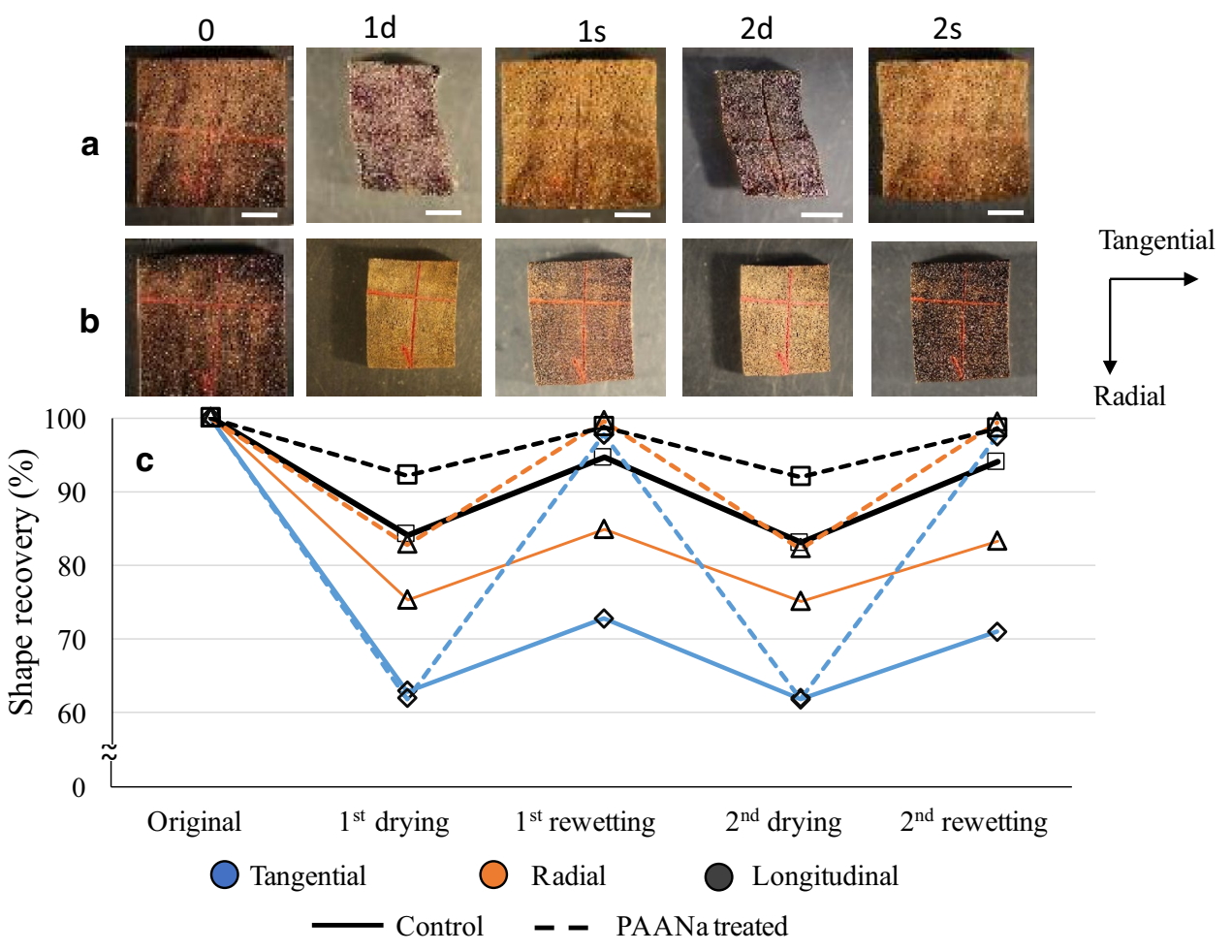

tangential shrinkage of untreated sample was approximately 1.5 times as great as the radial shrinkage; these values were about 37.16 and $24.68 \%$, respectively, while the longitudinal shrinkage reached $15.97 \%$ (Fig. $4 \mathrm{c}_{1 \mathrm{~d}}$ ). On the other hand, less deformation was observed in the PAANa-treated samples after the first natural drying process, especially in the radial and longitudinal directions, which showed shrinkage values of 17.23 and $7.79 \%$, respectively. However, shrinkage along the tangential direction was similar. This extreme radial, tangential, and longitudinal shrinkage could suggest that the cellulose underwent severe degradation [19].

After the first immersion in water, the PAANa-treated samples were almost $100 \%$ restored (Fig. $4 \mathrm{a}_{1 \mathrm{~s}}$ and $\mathrm{c}_{1 \mathrm{~s}}$ ) in all three dimensions, while the recovery rate was limited to around $10 \%$ in all directions in untreated samples (Fig. $4 b_{1 \mathrm{~s}}$ and $c_{1 \mathrm{~s}}$ ). This suggested that the irreversible adhesion of cell wall components, pores and degradation cavities of cell wall layers, occurs during the first drying process unless $\mathrm{WW}$ is treated with PAANa.

In the second drying-rewetting cycle, the PAANa-treated and untreated samples were air dried for 3 days. The dimensions of the PAANa-treated samples were similar to those observed after the first drying process (Fig. $4 \mathrm{a}_{2 \mathrm{~d}}$ and $\mathrm{b}_{2 \mathrm{~d}}$ ), while the untreated samples were slightly smaller than those after the first drying (Fig. $4 \mathrm{c}_{2 \mathrm{~d}}$ ). Surprisingly, even after the second rewetting process, the PAANa-treated samples exhibited perfect recovery to their original dimensions (Fig. $4 \mathrm{c}_{0}$ and $c_{2 s}$ ); however, only limited recovery was observed in the untreated samples; the recovery rates were even smaller than those observed after the first rewetting process.

According to a previous study [20], repeated drying and rewetting of degraded WW will lead to even greater shrinkage. Because of the degradation of polysaccharide substances in WW, the cellulose chains move closer together during the drying process, allowing the hydroxyl groups to form hydrogen bonds. When the collapsed ancient wood reabsorbs water, the newly formed hydrogen bonds can no longer accept water molecules, making the wood unable to swell to its original size [21].

At the end of the second rewetting cycle, the WW samples treated with PAANa regained $96 \%$ of their original volume, while the recovery rate was limited to $56 \%$ in the untreated samples. In other words, PAANa provided elasticity to the hygroscopic nature of the WW and, therefore, allowed the treated WW to recover its shape.

Although the recovery effect of the chemicals used on WW is of the greatest importance, the esthetic features are important aspects as well. The swollen PAANa is a transparent polymer; therefore, the natural color of treated wood was preserved (Fig. $4 \mathrm{a}_{1 \mathrm{~s}}$ and $4 \mathrm{a}_{2 \mathrm{~s}}$ ).

\section{Morphological investigations}

To clarify how the treatment affected the wood structure at the cellular level, scanning electron microscopy observation was carried out, and the results are shown in Fig. 5. The image clearly indicated the severe degradation of the cells, 


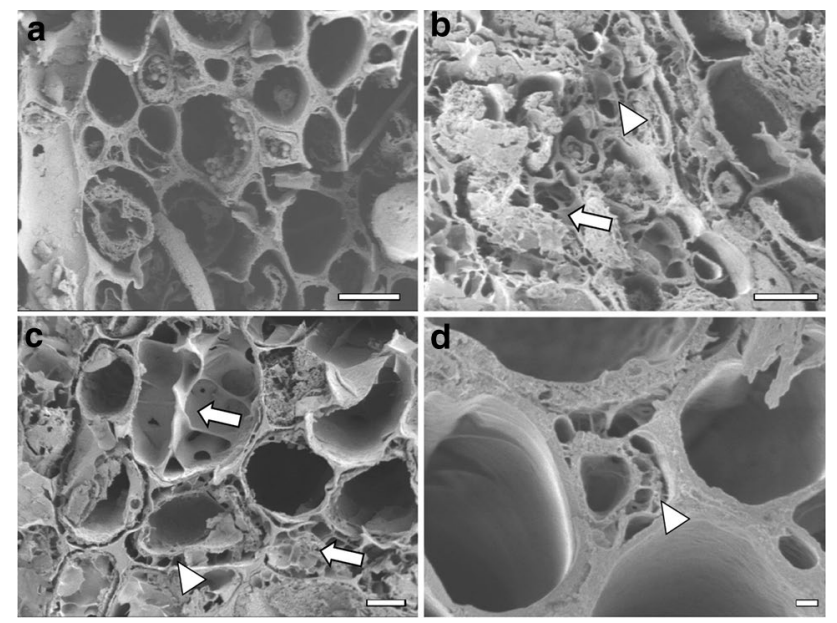

Fig. 5 The morphological features of the waterlogged, collapsed wood and re-swelled wood. a Freeze-dried WW without treatment, b air-dried WW treated with PAANa, c re-swelling of the PAANatreated wood, $\mathbf{d}$ localization of PAANa in inter-cellular space. Arrows PAANa located in cell lumina. Arrowhead PAANa located near the middle lamella. a-c scale bar $10 \mu \mathrm{m}$; d scale bar $1 \mu \mathrm{m}$

which were slightly shrunken due to the lack of cell wall integrity. Particularly, the inner secondary cell wall layers were almost completely destroyed by biological degradation and detached from the middle lamella as seen in Fig. 5a.

The PAANa-treated WW samples showed severe shrinkage during the natural drying process. Figure $5 \mathrm{~b}$ shows a transverse view of the PAANa-treated WW samples in which the fiber cells became elliptical. However, after immersion in water, the PAANa-treated WW exhibited obvious re-swelling of its wood tissues, in which the collapsed fiber cells were restored to a round shape (Fig. 5c). In the swollen treated wood, the crosslinked PAANa was found to be fully impregnated into WW samples investigated. This is due to the small molecular size of chemicals which enhances chemicals penetrate easily into the WW through the diffusion and permeation processes. The PAANa was clearly observed to be localized in the cell lumina and near the middle lamella, as shown in Fig. 5c. The inter-cellular space was well preserved (Fig. 5d). After repetition of the shrinkage-swelling processes, the final morphology of the swollen PAANa-treated WW was almost the same as its original shape.

Figure 6 shows the transmission electron microscopy images of the PAANa-treated and untreated cell layers. In the treated samples, the cell lumina and the area around the middle lamella were relatively electron dense. Since uranyl acetate and lead citrate stains are known to deposit in areas where water is miscible, the high density of the PAANatreated WW may be interpreted as evidence of the presence of the superabsorbent polymer PAANa, which increased the concentration of this staining agent.

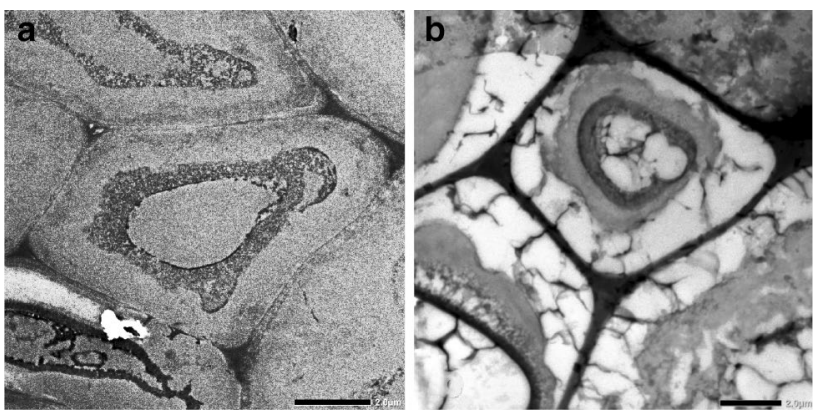

Fig. 6 Transmission electron microscopy images of WW transverse sections. a WW cell wall and b PAANa-treated WW cell wall. Scale bar $2 \mu \mathrm{m}$

In summary, the recoverability of WW was greatly enhanced by impregnation with PAANa. During the shrinkage-swelling processes, the final dimensions of the treated WW were almost restored to the initial dimensions. This regeneration cycle could be reproduced repeatedly. Because of superabsorbent properties of PAANa, the elasticity in the hygroscopic nature of the WW was improved and, therefore, shape recovery properties were achieved. Additionally, the PAANa is well known for its high structure stability in the polymer field; therefore, the presence of sodium in polymertreated wood would not cause the future danger for wood degradation in the long term.

\section{Conclusion}

Treatment with PAANa resulted in excellent shape recovery of WW after multiple drying-rewetting cycles, while the recovery was not complete in the untreated samples. This unique behavior is probably due to the restoration of the elasticity of the WW after PAANa treatment. In conservation and restoration of archaeological artifacts, the reversibility of the treated materials is one of the criteria. Therefore, a method to remove slightly crosslinked PAANa without damaging the wooden objects would also be a subject for further research. For suitably sized archaeological objects that fit the requirements of the proposed method, PAANa treatment could be used to provide resistance and recovery after unexpected drying, and may be used either as the primary conservation method or as a pretreatment in conjunction with other established conservation methods. However, when the samples are large and unwiedly, impregnation of acrylic monomers as a first step would be difficult and potentially problematic. In such cases, a method of surface treatment should be considered, as the deterioration of the WW is most severe in a limited area near the surface. This study has investigated on medium-degraded WW, further examinations on different classes of wood degradation 
are also needed. Although several further steps remain in the development of this method, the PAANa treatment presented in this study seems to have unique properties that can be applied practically for the conservation of WW.

Acknowledgements The authors appreciate Prof. Hiroshi Uyama, Osaka University for his kind guidance at the initial stage of investigation. The study was partly supported by Grants-in-Aid for Scientific Research (A) No. 25252033, Japan Society for the Promotion of Science, Research Institute of Sustainable Humanosphere (RISH) Cooperative Research (database) and RISH Mission Research V, Kyoto University. Transmission electron microscopy observation was done with Analysis and Development System for Advanced Materials in RISH, Kyoto University. Finaly, acknowledgements are extended to the Thang Long Research Center, Hanoi and the Institute of Archaeology, Vietnam Academy of Science and Technology for providing the archaeological wood materials.

\section{References}

1. Endo R, Sugiyama J (2013) Evaluation of cell wall reinforcement in feather keratin-treated waterlogged wood as imaged by synchrotron X-ray microtomography $(\mu \mathrm{XRT})$ and TEM. Holzforsch 67:795-803

2. Rowell RM, Barbour JR (1990) Archaeological wood: properties, chemistry and preservation. Advances in Chemistry Series 225. American Chemical Society, Washington DC

3. Jiachang C, Donglang C, Jingen Z, Xia H, Shenlong C (2009) Shape recovery of collapsed archaeological wood ware with active alkali-urea treatment. J Archaeol Sci 36:434-440

4. Uzielli L (2007) Wood science for conservation of cultural heritage. Proc Int Conf held by COST Action IE0601 Florence, Italy

5. Unger A, Schniewind AP, Unger W (2001) Conservation of wood artifacts. Springer, Berlin

6. Pearson C (1987) Conservation of marine archaeological objects. Butterworth Co Ltd., London

7. Hoffmann P, Peek R-D, Puls JSE (1986) Das Holz der Archäologen (in German). Holz als Roh-und Werkst 44:241-247

8. Hoffmann P (1993) Restoring deformed fine medieval turned woodware. In: ICOM Comm Conserv 10th Trienn Meet. Washington, DC, pp 257-261
9. Hoffmann P (1988) Zur Ruckformung mittelalterlicher Drechslerware (in German). In: Tl. II. Holzer mit Schwindungsschaden, 8. Arbeitsbl Restaur, Grup, pp 171-185

10. Chaumat G, Tran QK, Perre C, Lumia G (1999) Trials of shape recovering from collapsed waterlogged wood by treatment with $\mathrm{CO}_{2}$ supercritical fluid. In: Proc 7th ICOM-CC Work Gr Wet Org Archaeol Mater, pp 137-142

11. Jensen RL, Botfeldt K, Jensen JB, Lanchot VJ, Stratkvern K (2007) On treatments for swelling of dried-up waterlogged archaeological wood. In: Proc 10th ICOM Work Gr Wet Org Archaeol Mater, Amsterdam, pp 639-651

12. Xiang X, Shim H, Uyama H (2016) Dimensionally heterogeneous swelling-shrinkage behaviors of bacterial cellulose-crosslinked poly (acrylic acid) nanocomposite sheet. In: 23rd Annu Meet Cellul Soc Japan, p 143

13. Shim H, Xiang X, Karina M, Indrarti L, Yudianti R, Uyama $H$ (2016) One-dimensional shrinkage and swelling of crosslinked bacterial cellulose gel. Chem Lett 45:253-255

14. Ahmed EM (2015) Hydrogel: Preparation, characterization, and applications: a review. J Adv Res 6:105-121

15. Feder N, Sidman RL (1958) Methods and principles of fixation by freeze-substitution. J Biophys Biochem Cytol 4(5):593-600

16. Spurr AR (1969) A low-viscosity epoxy resin embedding medium for electron microscopy. J Ultrastruct Res 26:31-43

17. Reynolds ES (1963) The use of lead citrate at high $\mathrm{pH}$ as an electron-opaque stain in electron microscopy. J Cell Biol 17:208-212

18. Dong J, Ozaki Y, Nakashima K (1996) FTIR studies of conformational energies of poly (acrylic acid) in cast films. J Polym Sci 507-515

19. Berti S, Bettazzi F, Chimichi S, De Capua E, Gambetta A, Giachi G, Lazzeri S, Machioni N, Martena F, Paci S, Staccioli G (2002) Il legno ed il suo degrado nei manufatti recuperati nel porto antico di Pisa (in French). In: Proc 1 Congresso di Chimica dei beni Culturali "La scienza dell' Arte", pp 400-409

20. Ling L (2009) Unearthed archaeological wooden relics: generation, reply and permanent fixture. Sci Res China's Cult Reli 2:53-55

21. Jingran G, Jian L, Jian Q, Menglin G (2014) Degradation assessment of waterlogged wood at Haimenkou site. Frat ed Integrita Strutt 30:495-501 